\title{
Cytoplasmic p21 is a potential predictor for cisplatin sensitivity in ovarian cancer
}

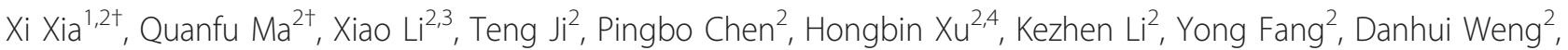 \\ Yanjie Weng ${ }^{2}$, Shujie Liao ${ }^{2}$, Zhiqiang Han², Ronghua Liư ${ }^{2}$ Tao Zhu², Shixuan Wang ${ }^{2}$, Gang Xu' ${ }^{2}$ Li Meng ${ }^{2}$, \\ Jianfeng Zhou ${ }^{2}$ and Ding $\mathrm{Ma}^{2^{*}}$
}

\begin{abstract}
Background: P21 (WAF1/Cip1) binds to cyclin-dependent kinase complexes and inhibits their activities. It was originally described as an inhibitor of cancer cell proliferation. However, many recent studies have shown that p21 promotes tumor progression when accumulated in the cell cytoplasm. So far, little is known about the correlation between cytoplasmic p21 and drug resistance. This study was aimed to investigate the role of p21 in the cisplatin resistance of ovarian cancer.
\end{abstract}

Methods: RT-PCR, western blot and immunofluorescence were used to detect p21 expression and location in cisplatin-resistant ovarian cancer cell line $\mathrm{C}_{1} 3^{*}$ and its parental line OV2008. Regulation of cytoplasmic p21 was performed through transfection of p21 siRNA, Akt2 shRNA and Akt2 constitutively active vector in the two cell lines; their effects on cisplatin-induced apoptosis were evaluated by flow cytometry. Tumor tissue sections of clinical samples were analyzed by immunohistochemistry.

Results: p21 predominantly localizes to the cytoplasm in C13* compared to OV2008. Persistent exposure to low dose cisplatin in OV2008 leads to p21 translocation from nuclear to cytoplasm, while it had not impact on p21 localization in C13*. Knockdown of cytoplasmic p21 by p21 siRNA transfection in C13* notably increased cisplatininduced apoptosis through activation of caspase 3. Inhibition of p21 translocation into the cytoplasm by transfection of Akt2 shRNA into C13* cells significantly increased cisplatin-induced apoptosis, while induction of p21 translocation into the cytoplasm by transfection of constitutively active Akt2 in OV2008 enhanced the resistance to cisplatin. Immunohistochemical analysis of clinical ovarian tumor tissues demonstrated that cytoplasmic p21 was negatively correlated with the response to cisplatin based treatment.

Conclusions: Cytoplasmic p21 is a novel biomarker of cisplatin resistance and it may represent a potential therapeutic target for ovarian tumors that are refractory to conventional treatment.

\section{Background}

Ovarian cancer is the sixth most common cancer among women and it leads to the highest mortality per year than any other cancers of the female reproductive system [1,2]. Cisplatin derivatives are first-line chemotherapeutic agents used for treatment of ovarian cancer. However, chemoresistance remains a major hurdle to successful therapy and results in low five-year survival

\footnotetext{
* Correspondence: dingma424@yahoo.com

+ Contributed equally

${ }^{2}$ Cancer Biology Research Center, Tongji Hospital, Tongji Medical College, Huazhong University of Science and Technology, Wuhan, Hubei, 430030, China

Full list of author information is available at the end of the article
}

rates $[2,3]$. Previous studies have suggested that resistance may be due to reduced drug accumulation [4], increased levels of glutathione and metallothionein [5] and enhanced DNA repair [6]. At present, it is widely accepted that the apoptotic response of cancer cells to chemotherapeutic drugs is the determining force for sensitivity to chemotherapy $[7,8]$. Many molecules, including XIAP [3], MKP3 [9], PI3K, Akt2 [10,11], PTEN [12], P-glycoprotein [13] and MDR [14], have been reported to be involved in the regulation of apoptosis and in the complicated signaling network that determines the fate of cancer cells, i.e., either "death" or "survival." Though much progress has been made, our
C Biomed Central

() 2011 Xia et al; licensee BioMed Central Ltd. This is an Open Access article distributed under the terms of the Creative Commons Attribution License (http://creativecommons.org/licenses/by/2.0), which permits unrestricted use, distribution, and reproduction in any medium, provided the original work is properly cited. 
recent studies have made efforts to predict the response of cancer cells to chemotherapeutic agents before treatment and to identify the possible alterations that mediate resistance.

P21 was the first identified inhibitor of cyclin/cyclindependent kinase (CDK) complexes [15]. Previous studies demonstrated that $\mathrm{p} 21$ could act as a "tumor suppressor" by binding to cellular CDK and proliferating cell nuclear antigen (PCNA), thereby inhibiting their function and leading to cell cycle arrest, leading to blockade of DNA synthesis and inhibition of cell proliferation $[15,16]$. Numerous studies that analyzed the expression of p21 in different types of human cancers have revealed that loss of p21 correlates with carcinogenesis and a poor prognosis in small-cell lung, colorectal, cervical and head and neck cancers [17-20]. In contrast, other findings have found that increased p21 expression was associated with tumor progression in ovarian, cervical, breast and esophageal squamous cell carcinomas [21-26]. This discrepancy could be due to the status of p21 itself and/or to differences in the histological types of cancers that have been analyzed. Besson et al. [27] suggested that control of the subcellular localization of p21 could represent an important regulatory switch from a nuclear tumor suppressor to a cytoplasmic oncogene. Once phosphorylated by Akt, p21 is induced to emigrate from the nucleus to the cytoplasm, protecting cells from apoptosis [28-31]. Additionally, clinical immunohistochemical analysis have proven that cytoplasmic p21 is a novel predictor of poor prognosis in breast cancer [32,33]. Although the role of p21 in the development of various types of human cancers has garnered much attention, little is known about its involvement in drug resistance.

Given that chemoresistance is a biological trait of tumor malignancy and has a direct influence on a patient's prognosis, this study was designed to explore whether cytoplasmic p21 correlated with cisplatin resistance in ovarian tumors. In addition, we sought to determine whether interfering with cytoplasmic p21 could enhance the susceptibility of cancer cells to cisplatin. Here, we report that in the cisplatin-resistant cell line $\mathrm{C} 13^{*}, \mathrm{p} 21$ is predominantly localized to the cytoplasm, while in the cisplatin-sensitive cell line OV2008, p21 is mainly restricted to the nucleus. Additionally, the exposure to low-dose cisplatin in OV2008 induced translocation of most $\mathrm{p} 21$ protein from nuclear to cytoplasm. Knockdown of cytoplasmic p21 by transfection of p21 siRNA into C13* cells notably enhanced their sensitivity to cisplatin. Inhibition of p21 translocation into the cytoplasm by Akt2 shRNA transfection in C13* cells significantly enhanced their sensitivity as well. Conversely, the accumulation of $\mathrm{p} 21$ in the cytoplasm by transfection of active Akt2 in OV2008 conferred resistance to cisplatin in OV2008 cells. Further analysis of clinical ovarian tumor samples by immunohistochemistry revealed that $\mathrm{p} 21$ was predominantly localized in the nucleus in the drug sensitive group. In contrast, p21 is mainly localized in the cytoplasm in the drug resistant group.

\section{Methods}

\section{Cell lines and cell culture}

The cisplatin-resistant ovarian cancer cell line $\mathrm{C} 13^{*}$ and its parental variant OV2008 were provided by Doctor Benjamin K. Tsang (Department of Obstetrics, Gynecology and Cellular and Molecular Medicine, University of Ottawa, Canada). Cells were maintained in RPMI-1640 supplemented with $2 \mathrm{mM}$ L-glutamine, $100 \mathrm{U} / \mathrm{ml}$ penicillin, $100 \mathrm{mg} / \mathrm{ml}$ streptomycin and $10 \%$ fetal bovine serum (FBS) at $37^{\circ} \mathrm{C}$ in a humidified atmosphere containing $5 \% \mathrm{CO}_{2}$.

\section{Clinical samples}

From 2004 through 2007, 40 patients who were diagnosed with ovarian carcinoma and received standard cisplatin-based intravenous chemotherapy after surgery at Tongji Hospital, Tongji Medical College, Huazhong University of Science and Technology were included in the study after obtainment of oral and written informed consents. Paraffin-embedded tumor tissue sections of each patient were prepared by the Department of Clinical Pathology. Information on histopathologic diagnosis was extracted from medical records and reviewed by a specialist in gynecologic pathology. The patients were selected and divided into treatment response and treatment non-response groups according to the CA125 criteria proposed by the Gynecological Cancer Intergroup (GCIC) [34]. Briefly, treatment response patients were defined as having at least a $50 \%$ reduction in CA125 levels, when compared to pretreatment samples, and this reduction must have been maintained for at least 28 days; the intervening value of CA125 must have been less than or equal to the previous value. Patients demonstrated any clinical evidence of progression, such as increased lump size and ascites, were excluded from the treatment response group. The remaining patients were classified as treatment non-response group. This study was reviewed and approved by the ethics committee of the medical faculty at the Tongji Hospital, Tongji Medical College, Huazhong University of Science \& Technology.

\section{Antibodies and reagents}

Antibodies against Akt, Ser473-phosphorylated Akt and p21 were purchased from Cell Signaling Technology, Inc. (Beverly, MA, USA). $\beta$-actin antibody and secondary goat anti-rabbit and goat anti-mouse alkaline 
phosphatase antibodies were purchased from Santa Cruz Biotechnology (Santa Cruz, CA, USA). Anti-caspase 3 antibody was purchased from Biolegend Co. (San Diego, CA, USA). RPMI-1640, FBS, Lipofectamine 2000 and Trizol reagent were purchased from Invitrogen Co. (Carlsbad, CA, USA). Cisplatin, MTT, DMSO, G418 and DAPI dye were obtained from Sigma Chemical Co. (St. Louis, MO, USA). The NE-PER cytoplasmic protein extraction kit was purchased from Pierce Co. (Rockford, IL, USA). The annexin-V/PI apoptosis detection kit was purchased from Promoter Biotech Ltd. (Wuhan, Hubei, China).

\section{Construction of plasmids}

A constitutively active Akt expression vector (AAkt2) and short hairpin RNA targeting Akt2 (Akt2Sh) were described previously $[11,35]$. The sequences of the p21 RNA interfering fragment (p21si) were as follows: sense, 5'- CUU CGA CUU UGU CAC CGA G -3'; anti-sense, 5'- C UCG GUG ACA AAG UCG AAG -3' [36]. The sequences of the mismatched fragment $(\mathrm{p} 21 \mathrm{sm})$ were: sense, 5'- CUC GAC UUC GUA CCC GAG -3': antisense, 5'- CUC GGG UAC GAA GUC GAG -3'.

\section{Transient transfection for RNAi targeting}

For RNAi targeting, C13* cells cultured in 6-well plates were transfected with indicated plasmids using Lipofectamine 2000. After 6 hours of incubation, the transfection solution was removed, and was replaced with fresh complete growth medium. 48 hours post-transfection the cells were assayed for the expression of p21 and treated with cisplatin for further experiment.

\section{Establishment of stable-expression cell lines of AAkt2 in OV2008 cells and Akt2sh in C13* cells}

OV2008 cancer cells were stably transfected with AAkt2 vector, $\mathrm{C} 13 *$ cancer cells were stably transfected with Akt2sh, using Lipofectamine 2000. Their corresponding empty vectors, i.e., pcDNA3.1 and pEGFPC1, were transfected as negative control. The cells were selected with G418. The concentration of G418 for selection and maintenance was $600 \mu \mathrm{g} / \mu \mathrm{l}$. After three weeks the G418-resistant cell pools were established and seeded into $100 \mathrm{~mm}$ dishes for further propagation.

\section{Real-time PCR}

Total RNA was isolated from each group of cells using Trizol Regent, according to the manufacturer's instruction. Real-time PCR amplifications were carried out using DNase I (Promega)-treated total RNA. Reactions were performed in a Stratagene MX3000P system using the Real-time PCR Master Mix (TOYOBO, Japan). P21 primer sequences were as follows: sense, 5'-CCT CTT CGG CCC GGT GGA C-3': anti-sense, 5'-CCG TTT
TCG ACC CTG AGA G-3'. GAPDH primer sequences were as follows: sense, 5'-ACG GAT TTG GTC GTA TTG GG-3'; anti-sense, 5'-TGA TTT TGG AGG GAT CTC GC-3'.

\section{Western blot analysis}

Total proteins were extracted by lysing cells in buffer containing $50 \mathrm{mM}$ Tris pH 7.4, $150 \mathrm{mM} \mathrm{NaCl}, 0.5 \%$ NP40, $50 \mathrm{mM} \mathrm{NaF}, 1 \mathrm{mM} \mathrm{Na} \mathrm{VO}_{4}, 1 \mathrm{mM}$ phenylmethylsulfonyl fluoride, $25 \mathrm{mg} / \mathrm{ml}$ leupeptin and $25 \mathrm{mg} / \mathrm{ml}$ aprotinin. The lysates were cleared by centrifugation, and the supernatants were collected. Cytoplasmic proteins were extracted using the N-PER cytoplasmic protein extraction kit according to manufacturer's instructions. Equal amounts of protein lysate were used for western blot analyses. Specific signals were visualized with NBT/BCIP.

\section{Cell viability assay using MTT}

Cells were seeded into 96-well plates, treated with different concentrations of cisplatin for 24 hours and then assessed using 3-[4, 5-dimethylthiazol-2-yl]-2, 5-diphenyltetrazolium bromide. Cell viability was determined by measuring the optical absorbance of cells at $570 \mathrm{~nm}$ wavelength and normalizing the values to the corresponding controls.

\section{Analysis of apoptosis by flow cytometry}

Cells were harvested, washed with PBS and stained with the annexin-V/PI apoptosis kit according to manufacturer's instructions. Analysis of apoptotic cells was performed using a FACScan flow cytometer, and the data were analyzed using cell fit software.

\section{Immunofluorescence}

Cells were trypsinized and plated onto chamber slides for 12 hours. After fixation in acetone, the slides were blocked with BSA, incubated with p21 antibody and rhodamineconjugated secondary antibody and counterstained with DAPI. Slides were then observed on a confocal laser-scanning microscope (Olympus IX81, Japan). P21 staining was categorized as negative, nuclear or cytoplasmic according to a standard described before [32]. Briefly, negative was defined as undetectable cytoplasmic or nuclear staining. Nuclear p21 was defined as the fraction of tumor cells with positive nuclear staining greater than or equal to that of positive cytoplasmic staining. Cytoplasmic p21 was defined as the fraction of cytoplasmic staining greater than that of nuclear staining. Five randomized fields were counted in order to calculate the percentage of cells that stained with anti-p21 antibody.

\section{Immunohistochemistry}

Paraffin-embedded tissue sections were deparaffinized. After antigen retrieval, slides were incubated with $3 \%$ 
$\mathrm{H}_{2} \mathrm{O}_{2}$ to inhibit endogenous peroxidase. Slides were then blocked with 5\% normal serum and incubated with anti-p21 antibody. For qualitative identification of specific antibody staining, the DAKO Envision+ system was used, according to manufacturer's instructions, as described below. After detection with chromogen diaminobenzidine, sections were counterstained with hematoxylin and mounted. For the negative control, all incubation steps were identical except that PBS was used instead of primary antibody. The immunoreactivity of p21 was categorized as negative, nuclear or cytoplasmic according to the standard decribed before [32].

\section{Image analysis}

Western blot images were captured and quantified using the ChemiImager 5500 system from the Alpha Innotech Corporation (San Leandro, CA, USA).

\section{Statistical analysis}

All experiments were repeated three times. The relationship between patients' clinical characteristics and results of p21 immunohistochemistry was assessed using the chi-squared $\left(\chi^{2}\right)$ test. Results expressed as mean \pm SD were analyzed using the Student t test. Differences were considered significant when $\mathrm{p}<0.05$. Data were analyzed using SPSS software version 13.0 (SPSS Inc., Chicago, IL).

\section{Results}

\section{Cisplatin-induced cytotoxicity and apoptosis in resistant} and sensitive cell lines

The MTT assay was used to examine the effects of cisplatin on the proliferation of $\mathrm{C}^{*} 3^{*}$ and OV2008 cells. The cells were exposed to different doses of cisplatin for 24 hours. As shown in Figure 1A, cisplatin decreased the viability of both $\mathrm{C} 13 *$ and OV2008 cells in a dosedependent manner. However, OV2008 cells were more sensitive to cisplatin, exhibiting an approximately 6-fold greater decrease in viability than $\mathrm{C} 13^{*}$ cells, as evaluated by the $\mathrm{IC}_{50}$ value $(\mathrm{p}<0.05)$. The difference between cisplatin-induced viability inhibition of the two cell lines peaked at $51.9 \%$ with $20 \mu \mathrm{M}$ cisplatin $(\mathrm{p}<0.05)$. By flow cytometry, we observed that cisplatin treatment increased apoptosis of OV2008 and C13* cells in a timedependent manner (Figure 1B). After 24 hours of exposure to cisplatin, there was at least a 2 -fold increase of apoptotic OV2008 cells when compared to C13* cells.

\section{Cytoplasmic p21 is more abundant in resistant cells than in sensitive cells}

Expression of p21 was examined by real-time PCR and western blot in the paired cell lines. There was no significant difference in the levels of p21 mRNA and total protein between the two cell lines (Figure 1C and 1D).
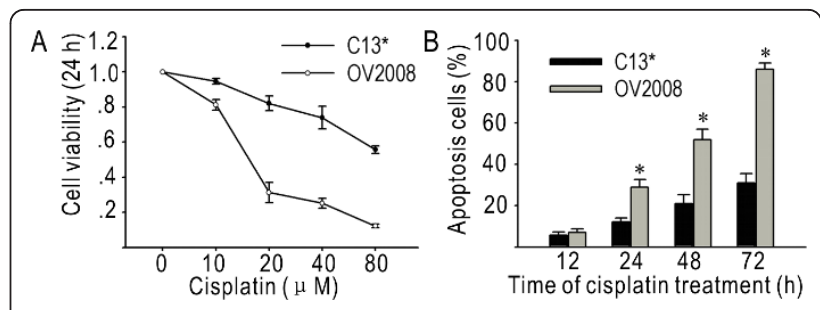

C

D
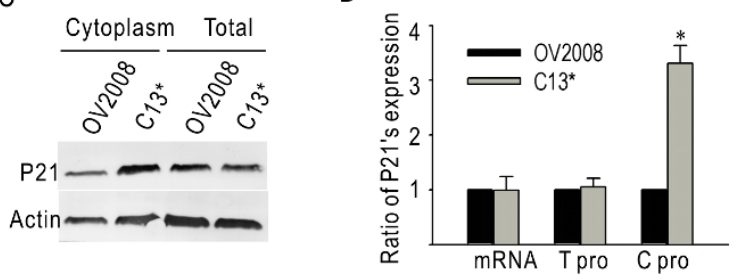

Figure 1 Cisplatin-induced cytotoxicity and apoptosis, and expression of p21 in C13* and OV2008 cells. (A) Dose-response curves for $\mathrm{C} 3^{*}$ and OV2008 cells following treatment with cisplatin. (B) Cisplatin-induced apoptosis at different time points $(20 \mu \mathrm{M})$. (C) Comparison of p21 protein levels between paired cell lines. (D) The p21 expression ratio of $\mathrm{C} 13^{*}$ to OV2008 cells. (*, $\left.\mathrm{p}<0.05\right)$.

The result of real-time PCR was normalized to the expression of GAPDH. The density of individual bands from western blot results were quantified and the ratios of $\mathrm{C} 13 *$ to OV2008 were calculated. The ratios of $\mathrm{C} 13 *$ to OV2008 in real-time PCR and western blot were 0.99 and 1.05, suggesting that $\mathrm{C} 13^{*}$ and OV2008 cells had equal expression levels of p21 (Figure 1D) ( $p>0.05$ ). By comparing cytoplasmic protein levels, we found that the amount of cytoplasmic p21 was much higher in $\mathrm{C} 13^{*}$ cells than in OV2008 cells (Figure 1C). The relative densities of the western blot bands shown in Figure $1 \mathrm{C}$ were calculated and the value was shown in Figure 1D. The results demonstrate that $\mathrm{C} 13^{*}$ cells have a 3.31 ( \pm 0.33 )-fold higher level of cytoplasmic p21 than do OV2008 cells $(\mathrm{p}<0.05)$. We used immunofluorescence and confocal microscopy to further validate these differences and found that in $\mathrm{C} 13^{*}$ cells p21 was predominantly located in cytoplasm (Figure 2A, upper panels), while in OV2008 cells p21 was mainly restricted in the nucleus (Figure 2A, upper middle panels). In addition, we determined the percentage of cytoplasmic p21 in $\mathrm{C}_{13}$ and OV2008 cells. As shown in Figure 2B, we found that in $\mathrm{C} 13 *$ cells $88.1 \% \pm 3.45 \%$ of p 21 was found in the cytoplasm, while in OV2008 cells 25.2\% \pm $4.8 \%$ of p21 was cytoplasmic $(\mathrm{p}<0.05)$.

\section{Persistent exposure to low dose cisplatin induces p21 translocation into cytoplasm in sensitive cells}

To examine the effect of cisplatin on p21, OV2008 and $\mathrm{C} 13^{*}$ cells were consecutively treated with low-dose of 5 $\mu \mathrm{M}$ cisplatin. Three weeks later, immunofluorescence and confocal microscopy were applied to detect p21's 


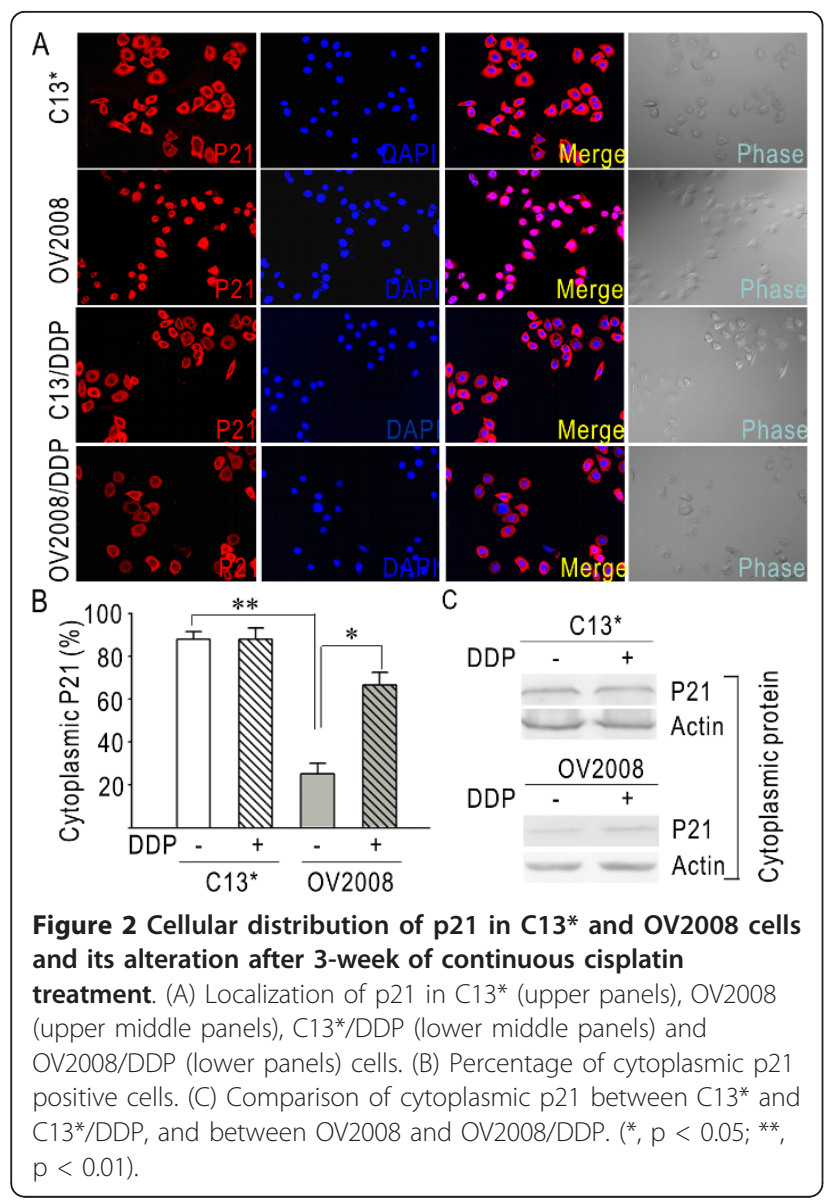

expression and distribution. In OV2008 cells treated with cisplatin $66.6 \% \pm 5.96 \%$ of p 21 was found in the cytoplasm (Figure 2A, lower panels), which was dramatically higher than in OV2008 cells not treated with cisplatin (Figure 2B) $(\mathrm{p}<0.05)$. However, in $\mathrm{C} 13^{*}$ cells no obvious changes of p21 sub-cellular location was observed after treatment with cisplatin (Figure 2A, lower middle panels). The percentage of cytoplasmic p21 in $\mathrm{C} 13^{*}$ cells that were exposed to cisplatin was $87.9 \% \pm$ $5.22 \%$, which was equal to parental control (Figure 2B) $(p>0.05)$. By measurement of western blot, the amount of cytoplasmic p21 was notably enhanced after treating with cisplatin in OV2008 (Figure 2C). However, there was no significant elevation in cytoplasmic $\mathrm{p} 21$ protein in $\mathrm{C}_{13}$ * cells after treating with cisplatin (Figure 2C).

\section{Knockdown of cytoplasmic p21 restores the sensitivity to cisplatin in $\mathrm{C} 3^{*}$}

To determine whether cytoplasmic p21 contributes to cisplatin resistance, RNA interference assay in $\mathrm{C} 13^{*}$ was applied to suppress p 21 that was mainly in the cytoplasm. C13* cells were transiently transfected with $\mathrm{p} 21 \mathrm{si}$ and its mismatched fragment of $\mathrm{p} 21 \mathrm{sm}$. By western blot, p21si transfection exhibited a dramatic decrease in cytoplasmic p21 compared with control groups (Figure 3A). After transfection, these cells were exposed to different concentrations of cisplatin for 48 hours. As shown in Figure $3 \mathrm{~B}$, the apoptosis rates in both $\mathrm{C} 13^{*} / \mathrm{p} 21 \mathrm{sm}$ and $\mathrm{C} 13 \% / \mathrm{p} 21$ si exhibited a concentration-dependent manner. The rates in p21si group were notably higher than their counterparts in mismatch-transfected group $(\mathrm{p}<$ 0.05). In the meantime, the effect of cytoplasmic p21 on cisplatin sensitivity was examined by caspase 3 activation. Using western blot, we found the level of cleaved caspase 3 protein in p21si group was significantly higher than its control groups (Figure 3C). These data indicate the reduction of cytoplasmic p21 endows cisplatin-resistant cells with increased sensitivity through activation of caspase 3.

\section{Inhibition of p21 translocation into cytoplasm enhances the sensitivity to cisplatin in $\mathrm{C} 13^{*}$}

Expression of Akt and p-Akt was examined by western blot in the paired cell lines. As shown in additional file 1, Figure S1, the protein level of p-Akt in $\mathrm{C} 13^{*}$ was markedly higher than in OV2008, while there was no significant difference in the Akt protein between the two cell lines. Short hairpin RNA targeting Akt2 was stably transfected into $\mathrm{C} 13^{*}$ cells. Total and cytoplasmic protein was extracted and analyzed by western blot. In contrast to control cells, the protein levels of Akt and pAkt were significantly decreased in Akt2Sh transfected cells. In addition, cytoplasmic p21 was remarkably decreased following RNA silencing of Akt2 (Figure 4A).

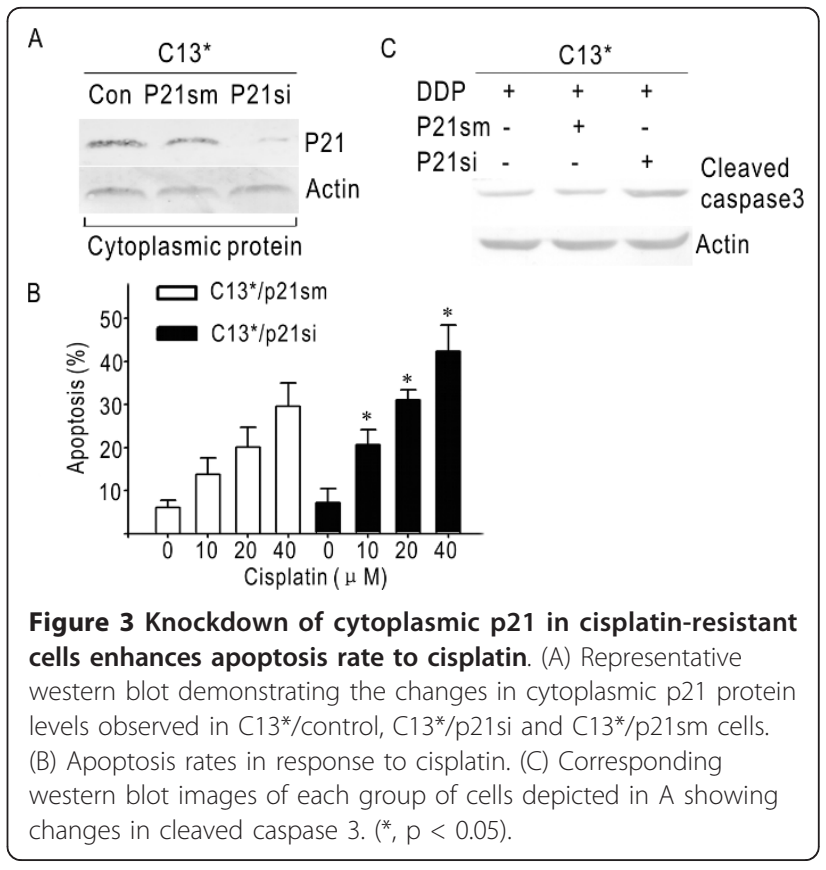




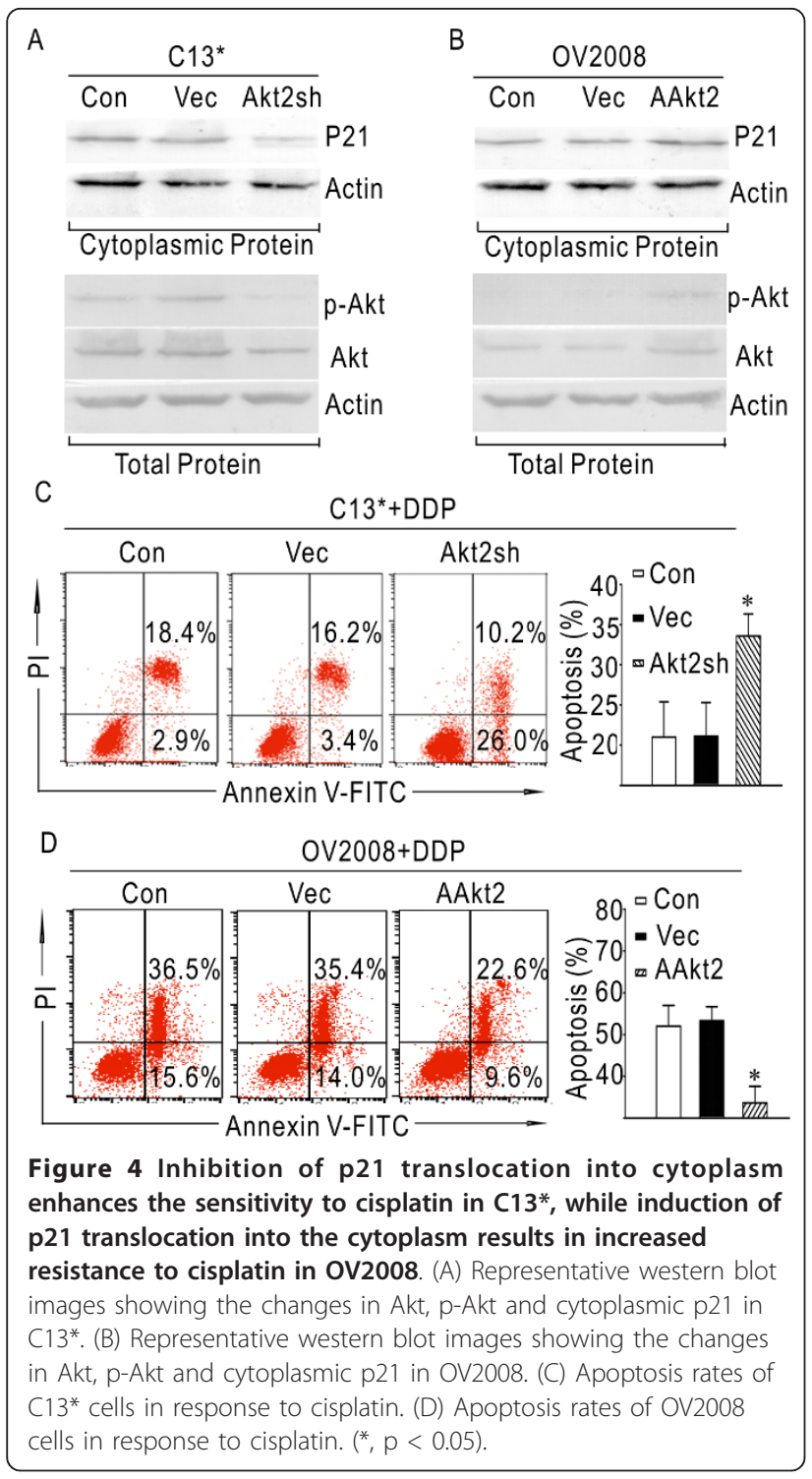

Flow cytometric analysis of cells exposed to $20 \mu \mathrm{M}$ cisplatin for 48 hours demonstrated that $\mathrm{C} 13^{*}$ cells transfected with Akt2 exhibited $33.6 \% \pm 2.7 \%$ apoptosis rate, which was higher than non-transfected control cells $(21 \% \pm 4.4 \%)$ and vector-transfected cells $(21.1 \% \pm 4.2 \%)$ $(\mathrm{p}<0.05$, Figure $4 \mathrm{C})$. Collectively, these results demonstrate that inhibition of cytoplasmic p21 through inactivation of Akt2 restores sensitivity of resistant ovarian cells to cisplatin.

\section{Induction of p21 translocation into the cytoplasm decreases sensitivity to cisplatin in OV2008}

The plasmid of AAkt2 was stably transfected into OV2008 cells. Total and cytoplasmic protein was extracted from the cells and analyzed by western blot. The protein levels of Akt and p-Akt were significantly increased in AAkt2 cells when compared to control cells (Figure 4B). Moreover, cytoplasmic p21 protein levels were markedly enhanced in AAkt2 transfected cells when compared to control cells (Figure 4B). Flow cytometric analysis of cells exposed to $20 \mu \mathrm{M}$ cisplatin for 48 hours demonstrated that OV2008 cells transfected with AAkt2 exhibited lower levels of apoptosis $(33.6 \% \pm$ $4.0 \%)$ than did non-transfected control cells $(52 \% \pm$ $5.1 \%)$ and vector-transfected cells $(53.3 \% \pm 3.4 \%)(\mathrm{p}<$ 0.05 , Figure $4 \mathrm{D})$. These results show that accumulation of p21 in cytoplasm by activation of Akt 2 impairs the susceptibility of sensitive ovarian cells to cisplatin.

\section{Expression of p21 in the cytoplasm is associated with cisplatin response in clinical samples}

Based on the results of our in vitro experiments, we decided to examine whether cytoplasmic p21 expression can serve as a marker for cisplatin resistance in ovarian cancer patients. Histological sections of ovarian cancer tissues were examined by immunohistochemistry for p21. The patients' clinical characteristics and results of p21 immunohistochemistry were shown in Table 1 . The number of patients with cytoplasmic and non-cytoplasmic p21 staining was 5 and 8 in the non-response group. However, in the response group, 2 and 25 patients were cytoplasmic and non-cytoplasmic respectively. These findings indicated that the proportion of cytoplasmic p21 staining was significantly higher in non-response group than in response group $(\mathrm{p}=0.027)$. Representative images of immunohistochemistry were shown in Figure 5, which demonstrated that p21 was predominantly localized in the cytoplasm in the nonresponse patient group (Figure 5A). In contrast, p21 is mainly localized in the nucleus in response group (Figure 5C). Additionally, cytoplasmic p21 staining was evaluated in patients at different clinical stages. In patients at stages III \& IV, the number of patients with

Table 1 Association of cytoplasmic p21 with clinicopathological parameters $(n=40)$

\begin{tabular}{llcccc}
\hline Characteristics & Total & \multicolumn{3}{c}{ p21's expression } & P\# \\
\cline { 3 - 4 } & & & Cytoplasmic & $\begin{array}{c}\text { Nuclear/ } \\
\text { Negative }\end{array}$ & \\
\hline Age & $\leq 50$ & 23 & 5 & $16 / 2$ & .677 \\
\multirow{2}{*}{ Histology*n } & Serous & 20 & 2 & $14 / 1$ & \\
& Mucous & 8 & 1 & $17 / 1$ & .407 \\
& Others & 8 & 3 & $6 / 1$ & \\
Stage & I \& II & 15 & 2 & $5 / 0$ & .691 \\
& III \& IV & 25 & 5 & $13 / 0$ & .027 \\
Cisplatin & Response & 27 & 2 & $17 / 3$ & \\
& Non- & 13 & 5 & $23 / 2$ & \\
& response & & & & \\
\hline
\end{tabular}

* Four patients are not available; $P$ values are calculated by Fisher exact test. 


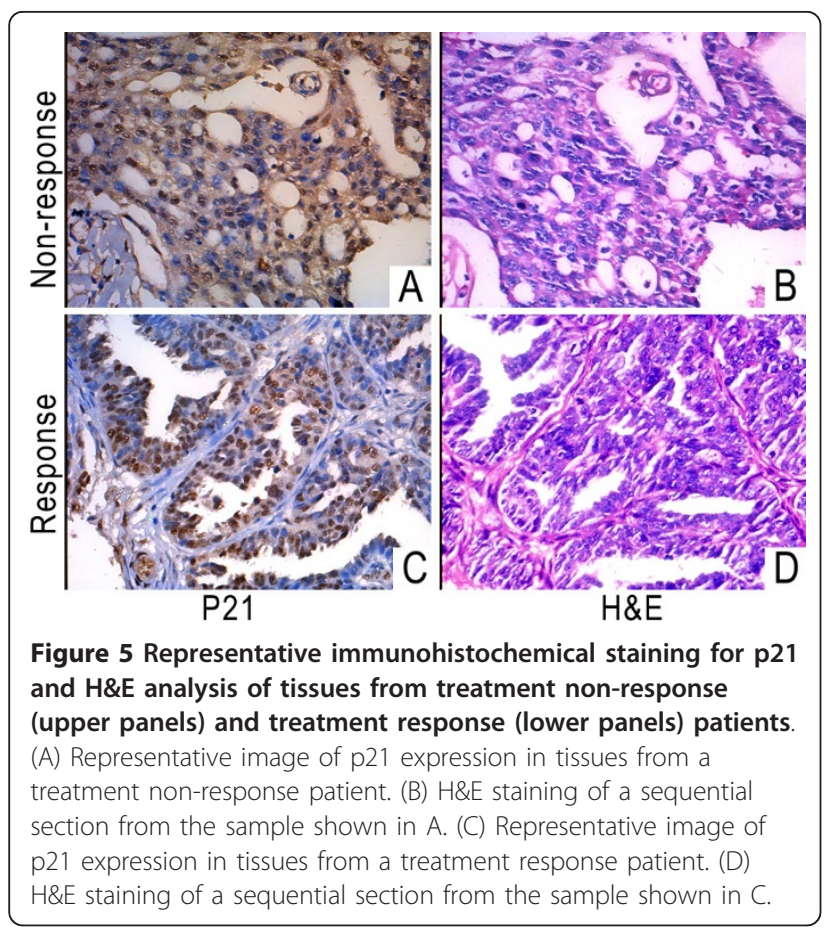

cytoplasmic and non-cytoplasmic p21 staining was 5 and 20 , respectively. In patients at stages I \& II, 2 patients exhibited cytoplasmic p21 staining, and 13 patients exhibited noncytoplasmic p21 staining $(p=0.691)$. This result suggested that there was no significant difference in the percentage of patients with cytoplasmic p21 staining between high stage and low stage ovarian tumors. Similarly, there was no significant difference in the levels of cytoplasmic p21 staining between serous and nonserous tumors $(p=0.407)$ or between groups of different ages $(p=0.677)$.

\section{Discussion}

It is well known that $\mathrm{p} 21^{\text {(Waf1/Cip1) }}$ in the nucleus functions as a tumor suppressor by binding to cyclin/CDK complexes and proliferating cell nuclear antigen $[15,16]$. However, recent studies [31,32] have revealed that p21 can be a paradoxical tumor promoting factor and has been associated with poor cancer prognosis due to its accumulation in the cytoplasm. Recently, Koster has reported cytoplasmic p21 expression levels determined cisplatin resistance in testicular cancer [37]. This study was aimed at exploring the relationship between cytoplasmic p21 and cisplatin resistance in ovarian cancer, and investigating whether regulation of cytoplasmic p21 could alter the response to the therapy.

The cisplatin-resistant cell line $\mathrm{C} 13^{*}$ used in this study was established after in vitro challenge of OV2008 cells, a line derived from one ovarian carcinoma patient without prior chemotherapy, with cisplatin [38,39]. Since
C13* and OV2008 cells shared the same genetic background and had minimum variation, they were superior to other cell lines and were chosen as optimal models for in vitro investigation of drug resistance. After confirming the expression levels and cellular distribution of p21 in the paired cell lines, we sought to determine whether it was influenced by cisplatin treatment and whether it was involved in cisplatin resistance. Longterm exposure to low-dose cisplatin resulted in p21 cytoplasmic translocation in cisplatin-sensitive cells, while the same treatment nearly had no effect on p21 cellular distribution in cisplatin-resistant cells. These results suggested p21's accumulation in cytoplasm was probably a protective response of sensitive cells to the drug, which helped them to escape from being killed by chemotherapeutics. Given that the endogenous p21 protein in resistant cells was mainly located in the cytoplasm, loss-of-function assay of cytoplasmic p21 was directly taken by RNA interference technology. Our results indicated knockdown of cytoplasmic p21 through p21 siRNA notably enhanced drug response in C13* cells. However, p21 transfection might not be the suitable strategy to illustrate the influence of increased cytocymic p21 because endogenous p21 in OV2008 was mainly restricted in the nuclear; The exogenous p21 transfected into OV2008 would probably mainly increase the nuclear amount instead of cytoplasmic amount. Thus, we increased the amount of cytoplasmic p21 by promoting its translocation from nuclear to cytoplasm in sensitive cells.

Zhou et al. reported that activation of phosphatidylinositol 3-kinase (PI3K)/Akt signaling can stimulate cytoplasmic accumulation of p21 [29]. There are three isoforms of Akt: Akt1, Akt2 and Akt3. All three isoforms share a high degree of amino acid sequence identity, especially within the kinase domain [40], and are activated by similar pathways in a PI3K-dependent manner. Overexpression of Akt2 has been found in $20 \%$ of human ovarian cancers [41], and increased Akt2 kinase activity has been found in approximately $30 \%$ of ovarian cancers [42]. Given these findings, we performed experiments where we altered the levels of cytoplasmic p21 by modulating Akt2 signaling. In OV2008 cells, a constitutively active AAkt2 plasmid was applied to activate PI3K/Akt signaling. Our results showed that the AAkt2 plasmid efficiently activated phosphorylation of Akt and, more importantly, significantly promoted the translocation of p21 into the cytoplasm. In the meantime, functional inhibition of cytoplasmic p21 was accomplished by short hairpin RNA silencing of Akt2 in C13* cells. Nevertheless, in fibroblasts and myoblasts, it has been suggested that the accumulation of $\mathrm{p} 21$ in the cytoplasm is stimulated by Akt1 [43]. The differences in our results might be ascribed to the different cell types used in the 
studies, similarity among three Akt isoforms and the mutual activation of the different isoforms. Therefore, the role of different Akt isoforms in the cytoplasmic translocation of p21 requires further investigation.

Caspase 3 activation is considered to be a key cellular component of the terminal and irreversible phase of apoptotic death caused by DNA damaging agents. In our experiments using flow cytometry, we found that the levels of cleaved caspase $3(17 \mathrm{kDa})$ were proportional to the rate of apoptosis. Previously, it was reported that p21 could bind to procaspase 3 [31] and prevent its conversion to mature caspase 3 , leading to the inhibition of apoptosis. In our experiments, it is likely that caspase 3 activation is inhibited by cytoplasmic p21; however, further studies are required to confirm this hypothesis.

By immunohistochemical analysis we found that a large proportion of tissues from treatment non-response tumors stained positive for cytoplasmic p21 (5 to 8) when compared to tissues from the treatment response group ( 2 to 25$)(\mathrm{p}=0.027)$. We also showed that there was no significant difference in the level of cytoplasmic p21 staining between high stage and low stage ovarian tumors ( $\mathrm{p}=0.691)$, and between patients of different ages $(\mathrm{p}=0.677)$. Furthermore, we compared cytoplasmic p21 levels in serous and non-serous tumors because the number of mucous and other types of tumors was limited. However, information on the prognosis and survival of the patients was not available; therefore, our investigation could not make a statistical analysis between cytoplasmic p21 and disease-free or survival rates.

\section{Conclusions}

Our in vitro experiments demonstrate cytoplasmic p21 is a novel biomarker in cisplatin resistance, and regulation of cytoplasmic p21 could alter the response of ovarian tumor cell lines to the drug. This finding supplements our previous studies $[11,12,34]$ and verifies that p21 is a downstream effector in the PI3K/Akt2 pathway that contributes to drug resistance.

\section{Additional material}

Additional file 1: Figure S1. Representative western blot depicting the Akt and p-Akt protein levels between $\mathrm{C}^{*} 3^{*}$ and OV2008 cells. Total protein was extracted from C13* and OV2008, and western blot was applied to compare the Akt and p-Akt expression between the paired cell lines.

\section{Abbreviations}

siRNA: small interference RNA; shRNA: short hairpin RNA; CDK: cyclindependent kinase; PI3K: phosphatidylinositol 3-kinase; PTEN: phosphatase and tensin homolog; XIAP: X-linked inhibitor of apoptosis; MKP3: mitogenactivated protein kinase phosphatase 3; MDR: multidrug resistance protein.

\section{Acknowledgements and Funding}

This work was supported by the National Science Foundation of China (81101971, 30571950, 30901586, 30801340), Major Innovation Medicine program (2009ZX09103-738), "973" Program of China (No. 2009CB521808), Science Foundation of Guangdong Province (No. B2011295, No. S2011040006012), Shenzhen Scientific Program (No.201002006, No.20110422597) and Nanshan Scientific Program (No. 2010028). We thank Dr. Li Cao for reviewing and collecting clinical samples, and Dr. Qiling Ao for analyzing the immunohistochemistry results.

\section{Author details}

'Department of Gynecology \& Obstetrics, Nanshan People's Hospital, Guangdong Medical College, Shenzhen, Guangdong, 518052, China. ${ }^{2}$ Cancer Biology Research Center, Tongji Hospital, Tongji Medical College, Huazhong University of Science and Technology, Wuhan, Hubei, 430030, China. ${ }^{3}$ Department of Pediatrics, Maternal and Child Health Hospital of Shenzhen, Southern Medical University, Shenzhen, Guangdong, 518038, China. ${ }^{4}$ Department of Gynecology \& Obstetrics, People's Hospital of Shenzhen, Shenzhen, Guangdong, 518020, China.

\section{Authors' contributions}

$X X$ and QM carried out the immunofluorescence staining, participated in functional assay and drafted the manuscript. XL, TJ, PC and HX participated in nucleus p21 siRNA sequence designing and silencing efficiency. $\mathrm{KL}$, YF and DW performed cell viability assay, western blot and RT-PCR. YW, SL and ZH collected clinical data, and carried out flow cytometry and immunohistochemistry assay. RL and TZ performed statistical analysis. GX participated in the data interpretation and provided expertise in molecular biological techniques. SW was responsible for writing and revising the manuscript. JZ, DM and LM participated in the design and coordination of the study. All authors have read and approved the final manuscript.

\section{Competing interests}

The authors declare that they have no competing interests.

Received: 3 April 2011 Accepted: 21 September 2011

Published: 21 September 2011

\section{References}

1. Permuth-Wey J, Sellers TA: Epidemiology of ovarian cancer. Methods $\mathrm{Mol}$ Biol 2009, 472:413-37.

2. Chien JR, Aletti G, Bell DA, Keeney GL, Shridhar V, Hartmann LC: Molecular pathogenesis and therapeutic targets in epithelial ovarian cancer. J Cell Biochem 2007, 102:1117-29.

3. Cheng JQ, Jiang X, Fraser M, Li M, Dan HC, Sun M, Tsang BK: Role of Xlinked inhibitor of apoptosis protein in chemoresistance in ovarian cancer: possible involvement of the phosphoinositide-3 kinase/Akt pathway. Drug Resist Updat 2002, 5:31-46.

4. Godwin AK, Meister A, O'Dwyer PJ, Huang CS, Hamilton TC, Anderson ME: High resistance to cisplatin in human ovarian cancer cell lines is associated with marked increase of glutathione synthesis. Proc Natl Acad Sci USA 1992, 89:3070-4.

5. Kelley SL, Basu A, Teicher BA, Hacker MP, Hamer DH, Lazo JS: Overexpression of metallothionein confers resistance to anticancer drugs. Science 1998, 241:1813-1815.

6. Parker RJ, Eastman A, Bostick-Bruton F, Reed E: Acquired cisplatin resistance in human ovarian cancer cells is associated with enhanced repair of cisplatin-DNA lesions and reduced drug accumulation. J Clin Invest 1991, 87:772-777.

7. Hajra KM, Tan L, Liu JR: Defective apoptosis underlies chemoresistance in ovarian cancer. Adv Exp Med Biol 2008, 622:197-208.

8. Fraser M, Leung BM, Yan X, Dan HC, Cheng JQ, Tsang BK: p53 is a determinant of $\mathrm{X}$-linked inhibitor of apoptosis protein/Akt-mediated chemoresistance in human ovarian cancer cells. Cancer Res 2003 63:7081-7088.

9. Chan DW, Liu WW, Tsao GS, Yao KM, Furukawa T, Chan KK, Ngan HY: Loss of MKP3 mediated by oxidative stress enhances tumorigenicity and chemoresistance of ovarian cancer cells. Carcinogenesis 2008, 29:1742-50.

10. Fraser M, Bai T, Tsang BK: Akt promotes cisplatin resistance in human ovarian cancer cells through inhibition of p53 phosphorylation and nuclear function. Int J Cancer 2008, 122:534-546. 
11. Xing H, Weng D, Chen G, Tao W, Zhu T, Yang X, Meng L, Wang S, Lu Y, Ma D: Activation of fibronectin/PI-3K/Akt2 leads to chemoresistance to docetaxel by regulating survivin protein expression in ovarian and breast cancer cells. Cancer Lett 2008, 261:108-19.

12. Wu H, Cao Y, Weng D, Xing H, Song X, Zhou J, Xu G, Lu Y, Wang S, Ma D Effect of tumor suppressor gene PTEN on the resistance to cisplatin in human ovarian cancer cell lines and related mechanisms. Cancer Lett 2008, 271:260-71.

13. Dong $X$, Mattingly CA, Tseng MT, Cho MJ, Liu Y, Adams VR, Mumper RJ: Doxorubicin and paclitaxel-loaded lipid-based nanoparticles overcome multidrug resistance by inhibiting P-glycoprotein and depleting ATP. Cancer Res 2009, 69:3918-26.

14. Xiao L, Gao R, Lu S, Lu MS, Liang ML, Ren LR, Wang ZH: Reversal effect of MDR1 and MDR3 gene silencing on resistance of A2780/taxol cells to paclitaxel. Zhonghua Fu Chan Ke Za Zhi 2007, 42:412-6.

15. Harper JW, Adami GR, Wei N, Keyomarsi K, Elledge SJ: The p21 Cdkinteracting protein Cip1 is a potent inhibitor of $\mathrm{G} 1$ cyclin-dependent kinases. Cell 1993, 75:805-16.

16. Yang ZY, Perkins ND, Ohno T, Nabel EG, Nabel GJ: The p21 cyclindependent kinase inhibitor suppresses tumorigenicity in vivo. Nat Med 1995, 1:1052-6.

17. Komiya T, Hosono Y, Hirashima T, Masuda N, Yasumitsu T, Nakagawa K, Kikui M, Ohno A, Fukuoka M, Kawase I: p21 expression as a predictor for favorable prognosis in squamous cell carcinoma of the lung. Clin Cancer Res 1997, 3:1831-5.

18. Zirbes TK, Baldus SE, Moenig SP, Nolden S, Kunze D, Shafizadeh ST, Schneider PM, Thiele J, Hoelscher AH, Dienes HP: Prognostic impact of p21/waf1/cip1 in colorectal cancer. Int J Cancer 2000, 89:14-8.

19. Lu X, Toki T, Konishi I, Nikaido T, Fujii S: Expression of p21WAF1/CIP1 in adenocarcinoma of the uterine cervix: a possible immunohistochemical marker of a favorable prognosis. Cancer 1998, 82:2409-17.

20. Kapranos N, Stathopoulos GP, Manolopoulos L, Kokka E, Papadimitriou C, Bibas A, Yiotakis J, Adamopoulos G: p53, p21 and p27 protein expression in head and neck cancer and their prognostic value. Anticancer Res 2001, 21:521-8.

21. Ferrandina G, Stoler A, Fagotti A, Fanfani F, Sacco R, De Pasqua A Mancuso S, Scambia G: p21WAF1/CIP1 protein expression in primary ovarian cancer. Int J Oncol 2000, 17:1231-5.

22. Barboule N, Baldin V, JOzan S, Vidal S, Valette A: Increased level of p21 in human ovarian tumors is associated with increased expression of cdk2, cyclin A and PCNA. Int J Cancer 1998, 76:891-6.

23. Cheung TH, Lo KW, Yu MM, Yim SF, Poon CS, Chung TK, Wong YF: Aberrant expression of p21(WAF1/CIP1) and p27(KIP1) in cervical carcinoma. Cancer Lett 2001, 172:93-8.

24. Bae DS, Cho SB, Kim YJ, Whang JD, Song SY, Park CS, Kim DS, Lee JH: Aberrant expression of cyclin D1 is associated with poor prognosis in early stage cervical cancer of the uterus. Gynecol Oncol 2001, 81:341-7.

25. Ceccarelli C, Santini D, Chieco P, Lanciotti C, Taffurelli M, Paladini G, Marrano D: Quantitative p21(waf-1)/p53 immunohistochemical analysis defines groups of primary invasive breast carcinomas with different prognostic indicators. Int J Cancer 2001, 95:128-34.

26. Sarbia M, Gabbert HE: Modern pathology: prognostic parameters in squamous cell carcinoma of the esophagus. Recent Results Cancer Res 2000, 155:15-27.

27. Besson A, Assoian RK, Roberts JM: Regulation of the cytoskeleton: an oncogenic function for CDK inhibitors? Nat Rev Cancer 2004, 4:948-55.

28. Kumar R, Hung MC: Signaling intricacies take center stage in cancer cells. Cancer Res 2005, 65:2511-5.

29. Zhou BP, Liao Y, Xia W, Spohn B, Lee MH, Hung MC: Cytoplasmic localization of p21Cip1/WAF1 by Akt-induced phosphorylation in HER-2/ neu-overexpressing cells. Nat Cell Biol 2001, 3:245-52.

30. Vivanco I, Sawyers CL: The phosphatidylinositol 3-Kinase AKT pathway in human cancer. Nat Rev Cancer 2002, 2:489-501.

31. Roninson IB: Oncogenic functions of tumor suppressor p21 (Waf1/Cip1/ Sdi1): association with cell senescence and tumor-promoting activities of stromal fibroblasts. Cancer Lett 2002, 179:1-14.

32. Xia W, Chen JS, Zhou X, Sun PR, Lee DF, Liao Y, Zhou BP, Hung MC: Phosphorylation/cytoplasmic localization of p21Cip1/WAF1 is associated with HER2/neu overexpression and provides a novel combination predictor for poor prognosis in breast cancer patients. Clin Cancer Res 2004, 10:3815-24.
33. Winters ZE, Leek RD, Bradburn MJ, Norbury CJ, Harris AL: Cytoplasmic p21WAF1/CIP1 expression is correlated with HER-2/neu in breast cancer and is an independent predictor of prognosis. Breast Cancer Res 2003, 5: R242-9.

34. Rustin GJ, Quinn M, Thigpen T, du Bois A, Pujade-Lauraine E, Jakobsen A, Eisenhauer E, Sagae S, Greven K, Vergote I, Cervantes A, Vermorken J: New guidelines to evaluate the response to treatment in solid tumors (ovarian cancer). J Natl Cancer Inst 2004, 96:487-8.

35. Weng D, Song X, Xing H, Ma X, Xia X, Weng Y, Zhou J, Xu G, Meng L, Zhu T, Wang S, Ma D: Implication of the Akt2/survivin pathway as a critical target in paclitaxel treatment in human ovarian cancer cells. Cancer Lett 2009, 273:257-65.

36. Zhang J, Attar E, Cohen K, Crumpacker C, Scadden D: Silencing p21(Waf1/ Cip1/Sdi1) expression increases gene transduction efficiency in primitive human hematopoietic cells. Gene Ther 2005, 12:1444-52.

37. Koster R, di Pietro A, Timmer-Bosscha H, Gibcus JH, van den Berg A Suurmeijer AJ, Bischoff R, Gietema JA, de Jong S: Cytoplasmic p21 expression levels determine cisplatin resistance in human testicular cancer. J Clin Invest 2010, 120:3594-605.

38. Hamilton TC, Lai GM, Rothenberg ML, Fojo AT, Young RC, Ozols RF: Mechanisms of resistance to cisplatin and alkylating agents. Cancer Treat Res 1989, 48:151-69.

39. Asselin E, Mills GB, Tsang BK: XIAP regulates Akt activity and caspase-3dependent cleavage during cisplatin-induced apoptosis in human ovarian epithelial cancer cells. Cancer Res 2001, 61:1862-8.

40. Manning BD, Cantley LC: AKT/PKB signaling: navigating downstream. Cell 2007, 129:1261-74

41. Altomare DA, Wang HQ, Skele KL, De Rienzo A, Klein-Szanto AJ, Godwin AK, Testa JR: AKT and mTOR phosphorylation is frequently detected in ovarian cancer and can be targeted to disrupt ovarian tumor cell growth. Oncogene 2004, 23:5853-7.

42. Yuan ZQ, Sun M, Feldman RI, Wang G, Ma X, Jiang C, Coppola D, Nicosia SV, Cheng JQ: Frequent activation of AKT2 and induction of apoptosis by inhibition of phosphoinositide-3-OH kinase/Akt pathway in human ovarian cancer. Oncogene 2000, 19:2324-30.

43. Héron-Milhavet $L$, Franckhauser $C$, Rana $V$, Berthenet C, Fisher D, Hemmings BA, Fernandez A, Lamb NJ: Only Akt1 is required for proliferation, while Akt2 promotes cell cycle exit through p21 binding. Mol Cell Biol 2006, 26:8267-80.

\section{Pre-publication history}

The pre-publication history for this paper can be accessed here: http://www.biomedcentral.com/1471-2407/11/399/prepub

doi:10.1186/1471-2407-11-399

Cite this article as: Xia et al:: Cytoplasmic p21 is a potential predictor for cisplatin sensitivity in ovarian cancer. BMC Cancer 2011 11:399.

\section{Submit your next manuscript to BioMed Central and take full advantage of:}

- Convenient online submission

- Thorough peer review

- No space constraints or color figure charges

- Immediate publication on acceptance

- Inclusion in PubMed, CAS, Scopus and Google Scholar

- Research which is freely available for redistribution

Submit your manuscript at www.biomedcentral.com/submit
C Biomed Central 